\title{
A Thermal Conductivity Model for Hydrating Concrete Pavements
}

\author{
Jin-Hoon Jeong ${ }^{1)}$ and Nakseok Kim ${ }^{2 *}$ \\ 1) Pavement Research Group, Highway \& Transportation Technology Institute, Korea Highway Corporation, Korea \\ ${ }^{2)}$ Division of Civil \& Environmental Engineering, Kyonggi University, Korea
}

(Received June 20, 2003; Accepted December 10, 2003)

\begin{abstract}
Hydrating concrete pavement is typically subjected to temperature-induced stresses that drive cracking mechanisms at early concrete ages. Undesired cracking plays a key role in the long-term performance of concrete pavement systems. The loss of support beneath the concrete pavement due to curling caused by temperature changes in the pavement may induce several significant distresses such as punch out, pumping, and erosion. The effect of temperature on these distress mechanisms is both significant and intricate. Because thermal conductivity dominates temperature flow in hydrating concrete over time, this material property is back-calculated by transforming governing equation of heat transfer and test data measured in laboratory. Theoretically, the backcalculated thermal conductivity simulates the heat movements in concrete very accurately. Therefore, the backcalculated thermal conductivity can be used to calibrate concrete temperature predicted by models.
\end{abstract}

Keywords : thermal conductivity, temperature, degree of hydration, maturity

\section{Introduction}

In recent years, materials research in concrete has shown that temperature induced crack development in concrete pavement has become an issue of great concern. It has been found that the development of temperature changes in a concrete paving in the first few days after placement are factors of early age restraint stresses and cracking related distress which ultimately influence the performance of the slab over its lifetime. ${ }^{1-3)}$ The knowledge of heat transfer in terms of the prediction of temperature as a function of time and key material properties is thus important to understand the cracking potential.

During the first few days after concrete is placed, the environmental conditions and the hydration of cement play a determinant role in the behavior of the concrete pavement. The environmental conditions influence boundary temperatures surrounding the concrete pavement. The hydration process generates heat within the concrete pavement. The temperature field at early ages of concrete pavement results from the heat of hydration and environmental conditions

\footnotetext{
* Corresponding author

Tel.: $+82-31-371-3368$

E-mail address: j-jeong@freeway.co.kr
}

imposed on its boundaries. The heat energy is transferred between a concrete boundary surface and the environment through convection, irradiation, solar radiation, and evaporation cooling while the heat energy is transferred within the concrete pavement by conduction.

Conduction is the transport of energy within concrete pavement due to a temperature difference. Thus, the determination of the material property of thermal conductivity $(k)$ is important from the standpoint of temperature distribution within a mass of concrete. Conduction can be viewed as the transfer of energy from more energetic molecules to less energetic molecules of concrete due to interactions between the molecules. The energy of the particles is related to the random translational motion as well as to the internal rotational and vibration motions of molecules in concrete. Higher temperature is associated with higher molecule energy, and when neighboring molecules collide, transfer of energy from more energetic molecules to less energetic molecules occurs. It has been known that the concrete with higher moisture content has higher values of thermal conductivity. ${ }^{4)}$ Therefore, higher rates of initial thermal conduction at early age of concrete are expected because of higher temperature differences and moisture content in concrete pavement. 


\section{Back-calculation of thermal conductivity}

The governing equation of heat transfer for temperature prediction in an early age concrete pavement taking heat of hydration and ambient temperature conditions into account is ${ }^{5,6)}$ :

$$
\frac{\partial}{\partial x}\left(k \frac{\partial T}{\partial x}\right)+Q_{h}(t, T)=\rho c_{p} \frac{\partial T}{\partial t}
$$

where

$T=$ temperature in concrete pavement $\left({ }^{\circ} \mathrm{C}\right)$

$t=$ time (hours),$\quad c_{p}=$ specific heat $\left(\mathrm{J} / \mathrm{kg} /{ }^{\circ} \mathrm{C}\right)$

$x=$ vertical coordinate in concrete pavement $(\mathrm{m})$

$k=$ thermal conductivity of concrete $\left(\mathrm{W} / \mathrm{m} /{ }^{\circ} \mathrm{C}\right)$

$\rho=$ concrete density $\left(\mathrm{kg} / \mathrm{m}^{3}\right)$

$Q_{h}=$ generated heat from heat of hydration of cement and external sources $\left(\mathrm{W} / \mathrm{m}^{3}\right)$

The thermal parameters in equation (1) are basic material properties determined by select laboratory and ASTM test procedures that are not elaborated here. Thermal conductivity can be calculated by transforming equation (1) as ${ }^{7)}$ :

$$
k=\frac{\rho c_{p} \frac{\partial T}{\partial t}-Q_{h}(t, T)}{\frac{\partial^{2} T}{\partial x^{2}}}
$$

The heat of hydration of concrete, $Q_{h}$, in equation (1) and (2) is the amount of heat which is released into the surroundings of the concrete due to hydration process. The heat of hydration is mathematically defined as ${ }^{8)}$ :

$$
Q_{h}=H_{u} C \alpha \frac{\lambda_{1} \kappa_{1}}{t_{1}} \frac{[\ln (\tau)]^{-\left(1+\kappa_{1}\right)}}{\tau} \cdot \exp \left[-\frac{E}{R}\left(\frac{1}{T+273}-\frac{1}{T_{r}+273}\right)\right](3)
$$

where

$$
\begin{aligned}
& H_{u}=\text { total heat of hydration }(\mathrm{J} / \mathrm{g}) \\
& C=\text { cement content }\left(\mathrm{g} / \mathrm{cm}^{2}\right) \\
& \lambda_{l}, \kappa_{l}, t_{l}=\text { hydration shape and time parameters } \\
& \tau=\text { age parameter }\left[=1+\frac{t_{e}}{t_{1}}\right] \\
& t_{e}=\text { equivalent age, } \alpha=\text { degree of hydration } \\
& E=\text { activation energy }(\mathrm{J} / \mathrm{mol}) \\
& R=\text { universal gas constant }\left(=8.3144 \mathrm{~J} / \mathrm{mol} /{ }^{\circ} \mathrm{C}\right) \\
& T_{r}=\text { reference temperature }\left(=20^{\circ} \mathrm{C}\right)
\end{aligned}
$$

The equivalent age, $t_{e}$, is predicted by Arrhenius maturity theory and then is used in the calculation of degree of hydration of concrete as ${ }^{8)}$ :

$$
t_{e}=\sum_{t=0}^{a g e}\left\{\exp \left[-\frac{E}{R}\left(\frac{1}{T+273}-\frac{1}{T_{r}+273}\right)\right] \cdot \Delta t\right\}
$$

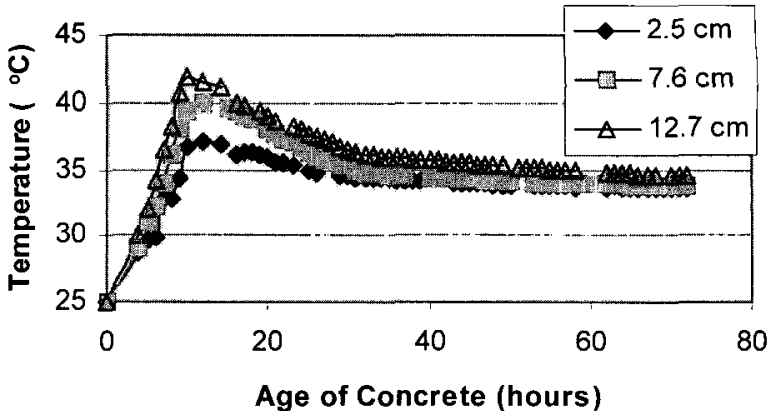

Fig. 1 Measured concrete temperature history ${ }^{9)}$

Table 1 Mix design $\left(1 \mathrm{~m}^{3}\right)$ for laboratory temperature monitoring $^{\text {9) }}$

\begin{tabular}{c|c|c|c|c|c|c|c}
\hline $\mathrm{W} / \mathrm{C}$ & $\begin{array}{c}\mathrm{W} \\
(\mathrm{kg})\end{array}$ & $\begin{array}{c}\mathrm{C} \\
(\mathrm{kg})\end{array}$ & $\begin{array}{c}\mathrm{S} \\
(\mathrm{kg})\end{array}$ & $\begin{array}{c}\mathrm{G} \\
(\mathrm{kg})\end{array}$ & $\begin{array}{c}\mathrm{AE} \\
(\mathrm{ml})\end{array}$ & $\begin{array}{c}\mathrm{WR} \\
(\mathrm{ml})\end{array}$ & $\begin{array}{c}\gamma_{\text {mix }} \\
\left(\mathrm{kg} / \mathrm{m}^{3}\right)\end{array}$ \\
\hline 0.41 & 136 & 335 & 699 & 1061 & 233 & 1044 & 2232 \\
\hline
\end{tabular}

$$
\alpha=\exp \left[-\lambda_{1}(\ln \tau)^{-\kappa_{1}}\right\rfloor
$$

As discussed previously, thermal conductivity dominates the temperature movements in concrete pavement. The values of the thermal conductivity vary with time and position and can be back-calculated by equation (2) using data collected from a field or a laboratory test. The back-calculated values are expected to yield valid estimates of thermal conductivity over time and to more accurately predict temperature in hardening concrete.

\section{Laboratory test program}

The M200 temperature sensors configured by ATEK (Arlington, Texas) were used to measure the temperature at different depths below the exposed surface of a concrete test specimen in a laboratory. The specimen was cylindrical in shape with diameter of $20.3 \mathrm{~cm}$ ( 8 inch) and height of $30.5 \mathrm{~cm}$ (12 inch) that was cast in a PVC ring. A PVC plate was used to seal the bottom end of the ring specimen. The mix proportions of the concrete specimen are shown in Ta-

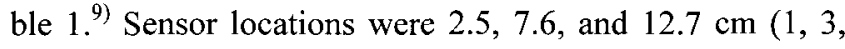
and 5 inch) below the exposed surface along the axis of the specimen.

The specimen was placed in a curing room right after placement. The room temperature and relative humidity were controlled to maintain $32{ }^{\circ} \mathrm{C}$ and $50 \%$. Temperature was measured from the sensors over a period of three days. During the early stages of the hardening process, the heat of hydration changed the concrete temperature. From the test result shown in Fig. 1, maximum temperatures occurred at 
11.1 hours and were $37.6{ }^{\circ} \mathrm{C}$ at $2.5 \mathrm{~cm}\left(1\right.$ inch), $40.1{ }^{\circ} \mathrm{C}$ at $7.6 \mathrm{~cm}$ ( 3 inch), and $42.3^{\circ} \mathrm{C}$ at $12.7 \mathrm{~cm}$ (5 inch) below the concrete surface, respectively.

\subsection{Total amount of heat}

A super insulated steel Qdrum semi-adiabatic calorimeter was used to calculate total amount of heat generation of concrete with mix proportions shown in Table 1. The Qdrum calorimeter measures the heat energy accumulated in the concrete due to heat of hydration and the heat flow through super-insulated wall of the Qdrum calorimeter. Concrete was placed in a $15.2 \times 30.5 \mathrm{~cm}(6 \times 12$ inch) plastic cylinder mold. This specimen was put inside the Qdrum calorimeter with a tightly sealed and insulated lid. Data collected from a datalogger connected to the Qdrum calorimeter indicated $485.3 \mathrm{~J} / \mathrm{g}$ of total amount of heat generation from the concrete specimen. ${ }^{10}$

\subsection{Activation energy}

Activation energy was determined in accordance with ASTM C $1074^{11)}$ using mortar cube specimens with similar mix proportions to the mortar in the concrete. Mortar was placed in brass cubic molds with $5.1 \mathrm{~cm}$ ( 2 inch) sides and the specimens were submerged into temperature-controlled water baths with 10,25 , and $50{ }^{\circ} \mathrm{C}$, respectively. The specimens were demolded immediately before compressive strength tests performed at $0.5,1,6,7$, and 14 days by using a universal hydraulic testing machine. Average values of three compressive strengths for each set of specimens were obtained as shown in Table $2 .^{10)}$

Ultimate compressive strengths for each curing temperature were estimated by interceptions of best-fit straight lines of reciprocal of average cube strength versus reciprocal of age as shown in Fig. 2.

Table 2 Strength history of mortar cubes cured in different temperature ${ }^{10)}$

\begin{tabular}{c|c|c}
\hline Temperature $\left({ }^{\circ} \mathrm{C}\right)$ & Age (days) & Strength $(\mathrm{MPa})$ \\
\hline \multirow{3}{*}{10} & 1 & 21.0 \\
& 6 & 85.3 \\
& 7 & 104.4 \\
& 14 & 221.1 \\
\hline \multirow{2}{*}{25} & 0.5 & 22.0 \\
& 1 & 44.7 \\
& 6 & 153.5 \\
& 14 & 228.1 \\
\hline \multirow{3}{*}{50} & 1 & 70.7 \\
& 6 & 176.3 \\
& 7 & 177.5 \\
& 14 & 244.2 \\
\hline
\end{tabular}

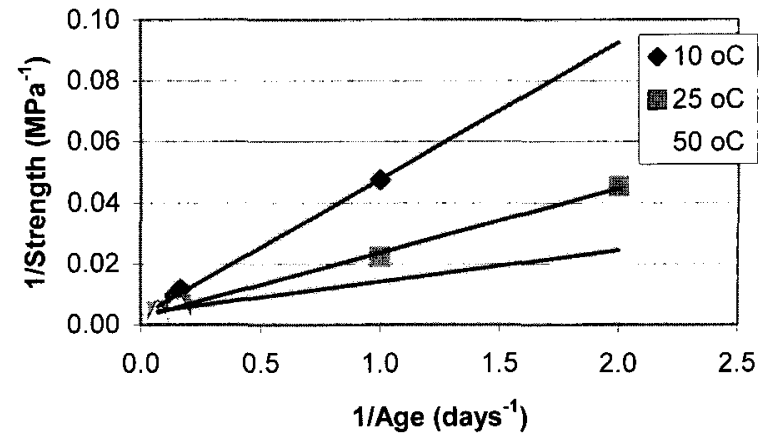

Fig. 2 Reciprocal of mortar cube strength versus reciprocal of age ${ }^{10)}$

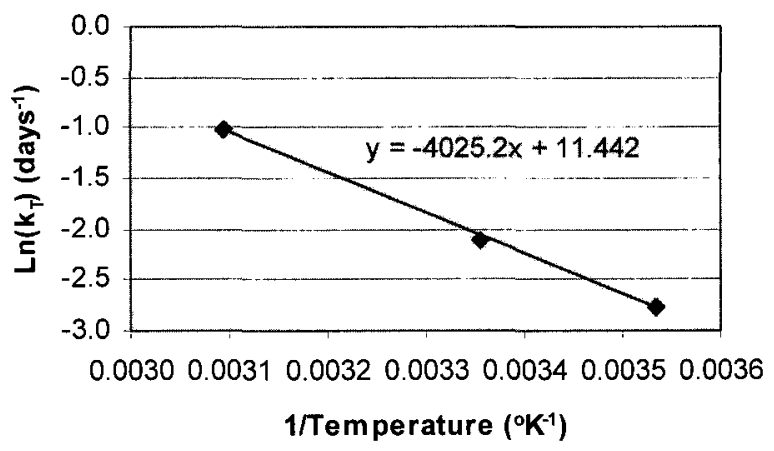

Fig. 3 Natural logarithm of k-values versus inverse absolute temperature

Activation energy of $33.5 \mathrm{~kJ} / \mathrm{mol}$ was determined by slope of best-fit straight line of the natural logarithm of reciprocal of age versus the reciprocal of absolute curing temperature as shown in Fig. 3. The slope of the line is the value of activation energy divided by the universal gas constant $\left(8.3144 \mathrm{~J} / \mathrm{mol} /{ }^{\circ} \mathrm{K}\right)$.

\subsection{Degree of hydration}

The curve of degree of hydration versus equivalent age has a similar trend to the curve of the relative strength versus equivalent age from the compressive strength test results for mortar cubes.

Therefore, degree of hydration can be represented by the relative strength. The hydration shape and time parameters $\lambda_{1}, \kappa_{1}$, and $t_{1}$ shown in equation (3) and (5) were determined by the relative strength of the mortar cubes using least square linear regression analysis. The values of the parameters for the mix proportion shown in Table 1 were found to be $0.73,1.56$, and 26 , respectively. ${ }^{10)}$ The curve of degree of hydration versus equivalent age obtained by equation (5) is shown in Fig. 4. 


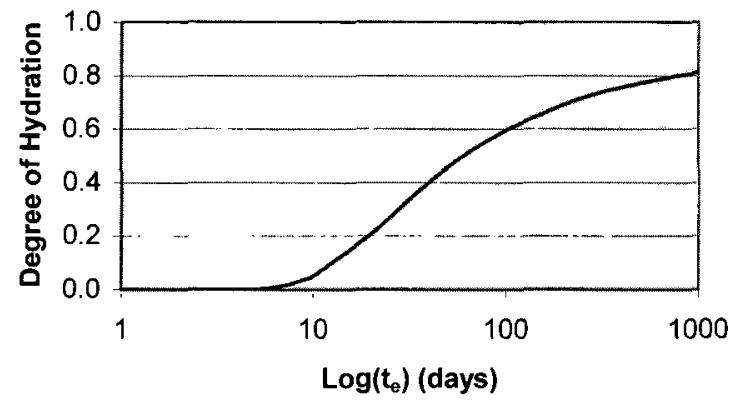

Fig. 4 Degree of hydration versus common logarithm of equivalent age ${ }^{10)}$

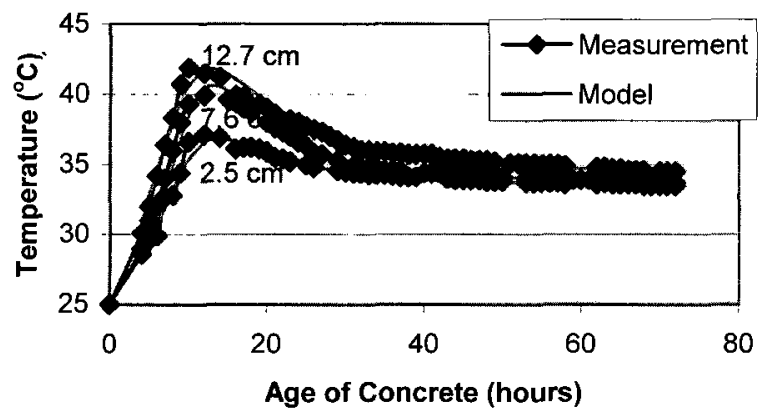

Fig. 5 Calculated concrete temperature history

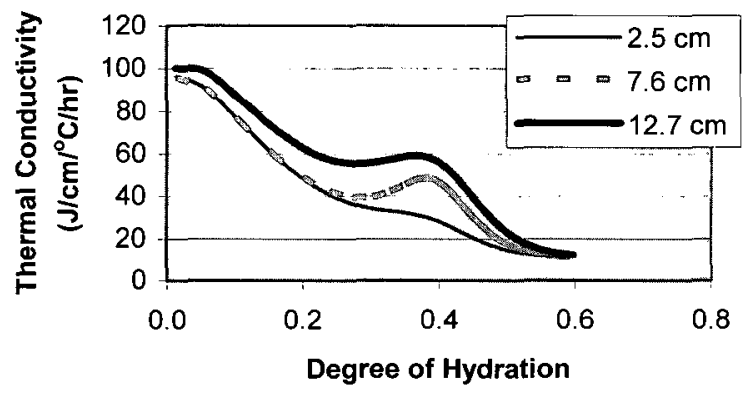

Fig. 6 Back-calculated thermal conductivity

\section{Modeling thermal conductivity}

The concrete temperature for the test conditions was defined as a function of curing time and vertical position in the concrete for each.

$$
T=\frac{a+b \ln (t)+c(\ln (t))^{2}+d(\ln (t))^{3}+e x+f x^{2}}{1+g \ln (t)+h(\ln (t))^{2}+i x+j x^{2}}
$$

where, $a$ to $j$ are the laboratory derived coefficients and the units of $T, t$, and $x$ are ${ }^{\circ} \mathrm{C}$, hours, and inches, respectively.
The temperature calculated by equation (6) agrees with the measured ones very well with R-square value of 0.972 as shown in Fig. 5. The values are only valid for the curing conditions and mixture proportions noted in Table 1.

Characterization of thermal conductivity is important in order to accurately model heat transfer in hydrating concrete. Using the concrete temperature model (equation (6)) and the parameters obtained from laboratory tests, thermal conductivities were back-calculated by equation (2). As discussed previously, equation (2) for the back-calculation of thermal conductivity was transformed from the governing equation of heat transfer derived from the first law of thermodynamics (the law of conservation of energy) and is expected to produce very reasonable values. Initially, the back-calculated thermal conductivities were high, and then it decreased to very small value as noted in Fig. 6. Initial higher thermal conductivity of fresh concrete was also suggested by previous researches. ${ }^{12,13)}$ They proposed 21 to $33 \%$ of decrease in thermal conductivity with curing time and the trends could be modeled as linear functions of degree of hydration. ${ }^{14)}$ However, Fig. 6 shows substantially larger decrease in back-calculated thermal conductivity than their suggestions. It can also be seen that the greater the distance from the drying surface, the higher the thermal conductivity of the concrete. The back-calculated thermal conductivity $(k)$ was assumed to vary with temperature $(T)$ and degree of hydration $(\alpha)$ of concrete as:

$$
k=\exp \left(a+b \alpha^{2} \ln \alpha+c T^{3}\right)
$$

where, $a$ to $c$ are the laboratory derived coefficients and the $\mathrm{R}$-square of the model is 0.947 . The values are also dependant upon curing conditions and mix proportions.

\section{Conclusions}

This study led to the following conclusions about modeling of thermal conductivity for newly placed concrete pavements:

1) Thermal conductivity was back-calculated by transforming the governing equation of heat transfer theory. A laboratory test using a cylindrical specimen where temperature data were collected was useful to collect data for this purpose. Total amount of heat, activation energy, and other parameters were also found in laboratory.

2) The initial higher back-calculated thermal conductivity significantly decreased with curing time.

3) The back-calculated thermal conductivity was modeled as a function of concrete temperature and degree of hydration. 
1. Powers, T.C., "A Discussion of Cement Hydration in Relation to the Curing of Concrete," Bulletin 25, Portland Cement Association, Skokie, IL, 1948, pp.1 9.

2. Copeland, L.E. and Hayes, J.C., "The Determination of Non-Evaporable Water in Hardened Portland Cement Paste," Bulletin 194, ASTM, Philadelphia, PA, 1953, pp. 70 74.

3. Barnes, P., "Structure and Performance of Cements," Applied Sciences Publishers, New York, NY, 1983.

4. Hsieh, C. K., Qin, C., and Ryder, E. E., "Development of Computer Modeling for Prediction of Temperature Distribution inside Concrete Pavement," Report FL/DOT/SO/ 90-374, Department of Mechanical Engineering, University of Florida, Gainesville, FL, 1989.

5. Incropera, F. P. and DeWitt, D. P., "Fundamentals of Heat and Mass Transfer," $4^{\text {th }}$ edition, John Wiley \& Sons, New York, NY, 1996.

6. Klemens, P.B., "Theory of the Thermal Conductivity of Solids," In R. P. Tye, Ed., Vol.1, Academic Press, London, 1969.

7. Jeong, J. H., "Characterization of Slab Behavior and Related Material Properties Due to Temperature and Moisture Effects," Ph.D. Dissertation, Texas A\&M University, College Station, TX, 2003.

8. Emborg, M., "Thermal Stresses in Concrete Structures at Early Ages," Doctoral Thesis, Lulea University of Technology, Sweden, 1989.
9. Jeong, J. H., Wang, L., and Zollinger, D. G., "A Temperature and Moisture Module for Hydrating Portland Cement Concrete Pavements," Proceedings, $7^{\text {th }}$ International Conference on Concrete Pavements, Vol.1, Orlando, FL, 2001, pp.9 22.

10. Wang, L., "Early Age Characterization of Concrete Temperature and Moisture Parameters," Ph.D. Dissertation, Texas A\&M University, College Station, TX, 2000.

11. ASTM C 1074, "Standard Practice for Estimating Concrete Strength by the Maturity Method," Annual Book of ASTM Standards, American Society for Testing and Materials, Philadelphia, PA, 1999.

12. De Shutter, G. and Taerwe, L., "Specific Heat and Thermal Diffusivity of Hardening Concrete," Magazine of Concrete Research, Vol.47, No.172, 1995, pp.203 208.

13. Khan, A. A. Cook, W. D., and Mitchell, D., "Thermal Properties and Transient Analysis of Structural Members during Hydration," ACI Materials Journal, Vol.95, No.3, 1998, pp.293 302.

14. Ruiz, J. M. et al., "Concrete Temperature Modeling and Strength Prediction Using Maturity Concepts in the FHWA HIPERPAV Software," Proceedings, $7^{\text {th }}$ International Conference on Concrete Pavements, Vol.1, Orlando, FL, 2001, pp.97 111. 